\title{
Relationship between Gestalt and usability heuristics in mobile device interfaces
}

\author{
Daniel Ripalda ${ }^{1}$, César Guevara ${ }^{1}$, and Alejandra Garrido ${ }^{2}$ \\ ${ }^{1}$ Indoamérica University, Mechatronics and Interactive Systems Research Center \\ Machala \& Sabanilla, Quito, Ecuador \\ ${ }^{2}$ LIFIA, Fac. de Informática, Univ. Nac. de La Plata \& CONICET \\ $50 \& 120,1900$ La Plata, Argentina \\ 1danielripalda@uti.edu.ec 2garrido@lifia.info.unlp.edu.ar
}

\begin{abstract}
While usability heuristics are universal concepts, visual references for using them in an application are limited, contradictory, and sometimes confusing, especially for novice developers. The present work has linked Nielsen's heuristics with Gestalt principles, which are the foundation of human perception, developed from psychology, and which have been used in art, design, and architecture, to understand how different visual stimulus can be interpreted by the human being. The heuristics, Match between system and the real world, Recognition rather than recall and Aesthetic and minimalistic design, have been linked with the Gestalt principles of Similarity, Proximity, Common direction, and Simplicity. This link is possible because Gestalt principles have certain conceptual similarities with usability heuristics, in addition to the fact that these fundamentals were identified in some mobile interfaces and are related to specific interactions. This work provides theoretical guidelines, visual references and practical examples on the use of some graphic components that are regularly used in mobile interfaces, such as buttons, menus, and sections; Besides, information is provided regarding how these visual components affect certain usability interactions such as learnability, efficiency, memorability, and usefulness.
\end{abstract}

Keywords: Gestalt, User Interfaces, Usability, Mobile, Agile Software Development.

\section{Introduction}

Producing a mobile application is usually a multidisciplinary work, which involves developers, designers, marketing specialists, and specific advisers according to the project; Generally, the software development methodology guides the steps that the team must follow, from eliciting requirements, building prototypes and evaluating the results with different tests before launching the application to the users. One of the crucial stages for an application is the production of prototypes for the Graphic User Interfaces (GUI), in which the development team seeks to balance functional aspects with visual aesthetics while trying to find efficiency to produce user satisfaction. [1]. Steve Jobs explained that those relationships are difficult to achieve in an application or device; he believed that there exists a kind of "magic" behind that process [2] and one way to achieve the goal could be the "taste" [3], both are abstract and ambiguous 
terms. This has led developers to believe that, to produce a GUI, in addition to the technical aspects for fulfilling the required functionality of the project, "some luck" is needed [4].

In the last years, important contributions have been made to improve interaction with devices, using concepts as heuristics and processes like User-Centered Design, Mockups, and Pattern-based Design. That knowledge has led to substantial advances to improve usability in interfaces, such as new applications or adaptations from desktop environments to mobile devices. In this context, the Gestalt Prototyping Framework from its theoretical approach [5], emerged as a proposal directed to usability experts, designers, and developers of mobile applications, to use visual references to build and evaluate interfaces of mobile devices, so that they can identify, prevent or correct errors in visual components of the GUI.

\section{Related work}

In 1994, Nielsen proposed 10 heuristics that lead the development team in the production of GUI. They are general guides to design the interactions that affect the usability of a system. These heuristics have been widely used as a reference, defining essential concepts for the Human-Computer Interaction (HCI) [6]. They became universal and are used until the present, having relevance from the evaluation of different prototypes [7]. However, at that time, interfaces were designed for desktop computers.

With the emergence of mobile technology, different researchers try to adapt Nielsen's heuristics, establishing parameters to measure the usability of mobile applications, generating important contributions such as Bertini's [8], who produced an evaluation model comparing it with the methods used until then. In this same context, Yanez-Gomez [9] configured a new list of usability parameters that can be used to evaluate mobile applications.

There is interest in understanding the relationship between aesthetics and HCI, and several investigations have reviewed the attributes and processes to design aesthetic interactions [10] [11]. Some discussions have focused on the relationship between the psychological perception of aesthetics and the perception of usability [12].

Gestalt principles describe the interaction of graphic components in space and how people perceive and understand these relationships; principles such as proximity, similarity, common direction among others, explain how people assimilate and react to the forms they visualize. For this reason, an interface can naturally use these concepts to generate, position, move, show and hide information, in a way that favors learning, execution, and memorization of certain tasks, reducing cognitive load, while in parallel generating favorable user experiences. Some applications have already used Gestalt parameters in the development of interfaces. Gómez claims to have noticed the presence of some of the principles and measured their impact on the interface quality of desktop applications [13]. Other applications have already used specific principles within their interfaces [14] [15] [16] [17], but without measuring their impact on the user experience so far. 


\section{Concepts applicable to an interface prototype}

The interfaces of mobile devices have different graphic elements to visualize the functional aspects of the application. To carry out tasks through the GUI, the user must perceive, interpret, and understand the purpose of the images that appear on the screen. This principle is the same that Gestalt uses to define the relationships that occur between figures that share the same space. Table 1 shows the theoretical link of usability heuristics, Gestalt principles, visual components, and usability interactions that are sought at different stages of prototype development.

Table 1. Components in which Heuristic and Gestalt concepts can be applied.

\begin{tabular}{|c|c|c|c|}
\hline Interface Component & Gestalt principle & Heuristic & Usability Interaction \\
\hline $\begin{array}{l}\text { Iconography } \\
\text { Colour } \\
\text { Buttons }\end{array}$ & Similarity & $\begin{array}{l}\text { Match between } \\
\text { system and the } \\
\text { real world }\end{array}$ & $\begin{array}{l}\text { Learning capacity and } \\
\text { Efficiency }\end{array}$ \\
\hline $\begin{array}{l}\text { Menus } \\
\text { Submenus } \\
\text { Pop up } \\
\text { Slide buttons }\end{array}$ & $\begin{array}{l}\text { Proximity } \\
\text { Common destiny }\end{array}$ & $\begin{array}{l}\text { Recognition } \\
\text { rather than recall }\end{array}$ & $\begin{array}{l}\text { Learning capacity } \\
\text { Efficiency } \\
\text { Memorability }\end{array}$ \\
\hline $\begin{array}{l}\text { Backgrounds } \\
\text { Dividers } \\
\text { Graphic style }\end{array}$ & Simplicity & $\begin{array}{l}\text { Aesthetic and } \\
\text { minimalistic } \\
\text { design }\end{array}$ & $\begin{array}{l}\text { Memorability } \\
\text { Utility }\end{array}$ \\
\hline
\end{tabular}

\subsection{Iconography, color, and buttons.}

The heuristic "Match between system and the real world" aims to make the different visual elements of an interface familiar to users, so they can associate them with their environment and context, positively identifying the actions that can be carried out in the application, without going through long periods to acquire basic skills.

This purpose can be achieved using the interface resources, if visual elements are used that are universal and recognizable by diverse human groups, regardless of the characteristics of their geographic, demographic, or sociocultural profiles.

According to Isidro Moreno [18] the icons - symbols can be read properly in the software if they can be associated with knowledge or experience encoded by an abstraction that facilitates the identification of the object, process, or idea that it represents. In the metaphor of navigating a system through an interface, current mobile devices combine peripheral hardware interactions, intermediate interactions that allow the selection of functions, and finally natural or gestural mimetic interactions.

Icons can be associated with concepts such as consistency, defined as a natural factor in the interactions that occur in an interface; the components allow us to carry out a task in a regular, fluid and uninterrupted way. The lack of consistency of an interface creates the possibility that there are different ways of carrying out the same task, these variations are the ones that can be confusing for the user.

The icons of an application must be easily recognizable, should have high contrast and simple shapes; the visual style, color, and shape of the iconography. The Gestalt principle of similarity contributes to the consistency of an interface, making it 
predictable learnable; these factors depend largely on the compatibility of an icon with the task it performs. For example, Figure 1 shows four icons that are used in different applications to save information, the task of the development team is to determine which of them is more compatible with the action that is going to be executed.

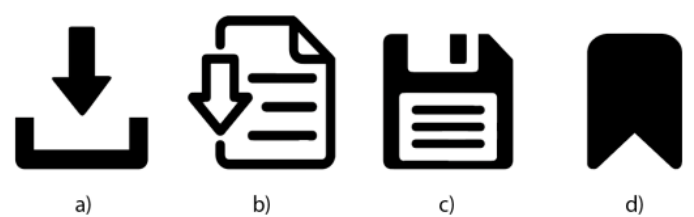

Fig. 1. The principle of similarity applied to the icons of a mobile application.

\subsection{Menu, submenu, Pop up and slide buttons.}

The Heuristic called "Recognition rather than recall", in an interface refers to the fact that essential actions must be identified in the foreground so that the user learns to perform them intuitively; The basic actions of the application should be grouped in such a way that categories and hierarchies are established naturally; for this, the elements must remain visible at all times, until the user becomes familiar with the application. In figure 2 you can see that the graphic similarity of the icons and their proximity generates that user perceives different menus and interface configurations.

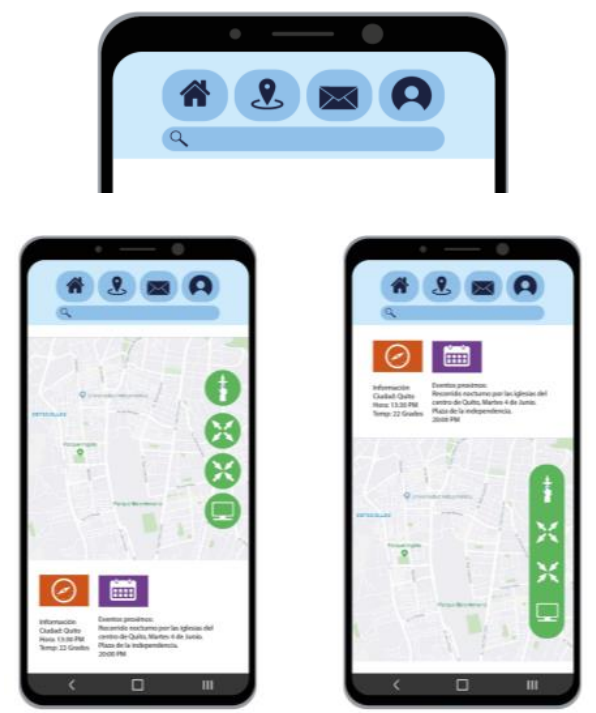

Fig. 2. The principle of proximity applied to the menus of a mobile application.

The Gestalt proximity principle causes that a group of icons can be naturally perceived as a menu, to create natural menus, the iconography can be grouped maintaining similarity in colors, shapes, positions, and orientations. By varying the orientation, the 
position of the icons, including the supports and other functional components, it is possible to maintain the hierarchy and organization of the interface.

On the other hand, the Gestalt principle of common direction describes that, if the objects move towards the same direction, they are perceived as a group. This concept can also be used to reorganize an interface after a change of orientation of the device.

\subsection{Backgrounds, dividers, and graphic style.}

The heuristics "Aesthetic and minimalistic design" points out that the design of an application should be minimalist, although not necessarily applied as a style, but rather as a guideline to reduce the amount of visual information provided to the user. In this sense, the Gestalt principle of Simplicity refers to how human beings perceive the forms even if they only appreciate a portion of them. These concepts allow the development team to narrow down the aesthetics-oriented graphics and orient it towards clarifying interface functions. Figure 3 shows how the graphic details of the interface are reduced, without changing the functions.

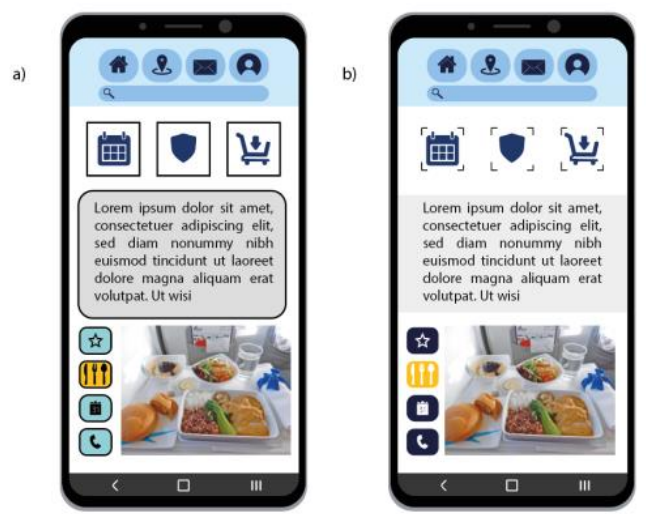

Fig. 3. The principle of Simplicity applied to reach a minimalist design.

\section{Conclusions and future work}

The Gestalt Prototyping Framework effectively links the basic notions of the Nielsen Heuristics with Gestalt principles, providing theoretical and visual references to understand how these models are integrated during the development of a GUI. Usability experts, designers, and developers of mobile applications can use these concepts to adapt, improve, or correct the prototypes of interfaces in projects, without interfering with the development methodology they have decided to use.

In the near future, we expect to obtain results from the application of our proposal in the development of high and low fidelity prototypes in the field of different projects. This will allow detecting the incidence of the Gestalt Prototyping Framework in the production time of applications, detection of errors in the interfaces, and improvements in different usability parameters. 


\section{References}

1. Marcus, A., «The cult of cute: The challenge of user experience design interactions,» 2002.

2. Brookey, R. A., «The magician and the iPod: Steve Jobs as industry hero. Leadership in the Media Industry,» 2006.

3. Elkind, P., «The trouble with Steve Jobs,» Fortune European Edition, 157, p. 54, 2008.

4. Crook, Izaak, «Diseño de Aplicaciones: Tutorial Paso a Paso para Diseñar una App,» 2019. [En línea]. Available: https://neoattack.com/diseno-aplicaciones/. [Último acceso: 2210 2019].

5. Ripalda, Daniel; Garrido, Alejandra; Guevara, César, «Gestalt framework in the design of interfaces for mobile devices: Theoretical approach,» de 13th Iberian Conference on Information Systems and Technologies (CISTI), Cáceres, Spain, 2018.

5. NIELSEN, Jakob., 10 usability heuristics for user interface design., Nielsen Norman Group, 1995.

7. Nielsen, J., \& Molich, R., «Heuristic evaluation of user interfaces.,» de In Proceedings of the SIGCHI conference on Human factors in computing systems. ACM, 1990.

3. Bertini, E., Gabrielli, S., Kimani, S., Catarci, T., \& Santucci, G., «Appropriating and assessing heuristics for mobile computing,» Proceedings of the working conference on Advanced visual interfaces, pp. 119-126, 2016.

7. Yáñez Gómez, R., Cascado Caballero, D., \& Sevillano, J. L., «Heuristic evaluation on mobile interfaces: A new checklist.,» The Scientific World Journal, 2014.

10. Lim, Y. K., Stolterman, E., Jung, H., \& Donaldson, J., «Interaction gestalt and the design of aesthetic interactions.,» Proceedings of the 2007 conference on Designing pleasurable products and interfaces, pp. 239-254, 2007.

11. Norman, D. A., Emotional Design: Why We Love (or Hate) Everyday Things, New York: Basic Books, 2005.

12. Hassenzahl, M., «The interplay of beauty, goodness, and usability in interactive products. Human-Computer Interaction,» pp. 319-349., 2004.

13. J. Gómez, Measuring the Impact of Gestalt Theories on Graphic user interface design, 2011.

14. Xiang, P., Yang, X., \& Shi, Y., Web page segmentation based on gestalt theory, In Multimedia and Expo, 2007 IEEE International Conference on (pp. 2253-2256). IEEE., 2007.

15. Looije, R., te Brake, G. M., \& Neerincx, M. A., Usability engineering for mobile maps., Proceedings of the 4th international conference on mobile technology, applications, and systems and the 1st international symposium on Computer human interaction in mobile technology, 2007.

16. Gong, J., \& Tarasewich, P., Guidelines for handheld mobile device interface design, Proceedings of DSI 2004 Annual Meeting (pp. 3751-3756)., 2004.

17. King, M. T., Grunbock, C., Mannby, C. F., \& Valenti, W., U.S. Patent Application 12/961,407., 2010.

18. I. Moreno, «Iconos hipermedia: La llave interactiva,» Revista ICONO14 Revista científica de Comunicación y Tecnologías emergentes, pp. 123-135, 2003. 